\title{
Tcach, C. (Comp.). (2017). Córdoba Bicentenaria. Claves de su historia contemporánea. 2 da ed. Córdoba: UNC, 544 pp.
}

\author{
María del Mar Solís Carnicer ${ }^{1}$
}

Esta segunda edición de Córdoba Bicentenaria no es una mera reimpresión de la primera. Si bien contiene los mismos artículos, incluye una nueva introducción por parte del coordinador de la obra, César Tcach, relativo a los mitos y metáforas con las que se ha intentado explicar la política cordobesa. La nueva versión de este libro -publicado originariamente en 2010- incluye muy buenas imágenes fotográficas de archivo, evidenciando un importante salto en la calidad de la impresión. Reúne diecisiete trabajos sobre diferentes aspectos de la historia de Córdoba que abarcan un período de dos siglos, escritos por importantes especialistas en cada uno de los temas que abordan, todos ellos discutidos previamente en los equipos de investigación a los que pertenecen, presentados en jornadas o eventos académicos o incluso, algunos de ellos, son síntesis de trabajos de más largo alcance (tesis de maestría o doctorado) lo que, en el resultado final, da un libro diverso por sus temáticas y enfoques pero coherente en sus objetivos y resultados.

El libro puede leerse de diferentes maneras, la primera y más sencilla po- dría ser la de seguir el desarrollo cronológico de la historia política de Córdoba desde las primeras décadas del siglo XIX hasta fines del siglo XX y podrá tenerse de esa lectura un panorama general de los procesos políticos y de la cultura política cordobesa, de sus cambios y continuidades. Sin embargo, no todos los trabajos de la compilación enfocan los problemas desde una misma perspectiva. Eso no solamente resulta muy estimulante para el lector académico, sino que también es una cantera de inspiración para posibles nuevas investigaciones. Como toda historia bien hecha no se trata de trabajos cerrados sino que cada uno de ellos abre un abanico de nuevas posibilidades de indagación.

Otra forma de leer el libro, entonces, es a partir de los problemas de investigación que plantea, las «claves» como señala el título de la obra. De ese modo se pueden agrupar a los trabajos que se preguntan, por ejemplo, sobre la dinámica de las relaciones entre gobierno-oposición en diferentes períodos, los que estudian la construcción del Estado provincial y su ingeniería institucional, o los que abordan el papel de los parti-

\footnotetext{
${ }^{1}$ Doctora en Historia. Profesora Titular por concurso de Historia Argentina Contemporánea y Directora de la Especialización en Historia Regional de la Facultad de Humanidades de la Universidad Nacional del Nordeste. Investigadora Adjunta del Consejo Nacional de Investigaciones Científicas y Técnicas (IIGHI- UNNE/CONICET). Contacto: marimarsolis@yahoo.com.ar
} 
dos políticos y de otros actores políticos relevantes de la historia cordobesa como la Iglesia Católica, los sindicatos y el movimiento estudiantil. Las preguntas sobre la democracia, la dictadura, la cultura política y las identidades recorren también gran parte de los trabajos que se incluyen en el libro.

Las relaciones gobierno-oposición son estudiadas, por ejemplo, en los artículos de Javier Moyano quien se concentra en la últimas décadas del siglo XIX y principios del siglo XX en «El clivaje entre clericales y liberales en la política cordobesa entre 1890 y 1930. Sus alcances y límites como causa de alianzas y conflictos entre la dirigencia», también se acerca a ese tema Emilse Pons, pero en ese caso para los años sesenta en «El fracaso del proyecto autoritario en Córdoba y la eclosión de la movilización popular (1966- 1973)»y lo mismo hace Gabriela Closa en sus dos artículos al analizar la etapa de 1983 en adelante en «La recuperación de la democracia y los gobiernos radicales. Angeloz y Mestre (1983-1999)» y en «Las transformaciones en el peronismo de Córdoba».

La construcción del Estado provincial y de una ingeniería institucional particular, es el objeto principal del capítulo de Silvia Romano «Las nuevas fuentes de legitimación del poder y sus protagonistas en la configuración del sistema republicano y representativo en la provincia de Córdoba (1821- 1855)» que examina los aspectos y mecanismos de la representación política de la campaña cordobesa en una etapa en la que los valores del antiguo régimen se resignifican. César Tcach y Marta Philp retoman la cuestión en «Estado y Parti- do peronista en Córdoba: una interpretación», texto que ayuda a dilucidar la reformulación de ese diseño institucional y las construcciones de sentido que emanaban del mismo durante los años del peronismo.

Otro gran tema/problema que es abordado en el libro es el de los partidos políticos. Resulta muy interesante comprender el proceso de organización y reconfiguración de los tres partidos que fueron los principales protagonistas de la historia política de Córdoba: el partido demócrata, el partido radical y el partido peronista, temas que son analizados en los dos trabajos de Javier Moyano que se incluyen en el libro, tanto en el artículo que ya mencionamos como en «Los gobernadores del Partido Autonomista Nacional y del Partido Demócrata entre la revolución de 1890 y el triunfo radical de 1928». El radicalismo es el objeto de indagación del artículo de Gardenia Vidal «El internismo radical en Córdoba durante los primeros años de competencia partidaria» en el que desentraña los rasgos particulares de ese partido a principios del siglo XX, su incapacidad para mantener la unidad y la presencia influyente de dirigentes católicos. También se ocupa del radicalismo César Tcach en «Retrato político de la Córdoba de los treinta» en el que analiza las transformaciones operadas en el seno del partido durante el sabattinismo en un marco histórico signado por el contraste con el dominio conservador en el orden nacional.

Sobre el peronismo de los años setenta se ocupan Alicia Servetto y Gabriela Closa. La primera en «Tensiones y contradicciones del tercer gobierno peronista» indaga sobre la violencia es- 
tatal y la creciente conflictividad que se vivió en Córdoba durante los gobiernos peronistas de 1973-1976 en el que hicieron eclosión las diferencias internas del partido; la segunda analiza la situación del peronismo luego del retorno a la democracia en 1983. Cada uno de estos trabajos aborda la cuestión de manera diferente pero con algunos elementos comunes: las relaciones con el gobierno nacional o las autoridades nacionales de los partidos o el estudio de las élites políticas.

En cuanto a este último tema, surge de estos trabajos un rasgo que resulta muy llamativo, la permanencia en espacios de poder de algunos apellidos o de algunas familias a lo largo de todo el siglo XX. Se destaca aquí particularmente el trabajo de Cristina Boixados «La ciudad en disputa. Prácticas de enriquecimiento de la elite dirigente a fines del siglo XIX» con una temática interesante y actual, trabajada de manera muy inteligente a través de fuentes judiciales donde se indaga sobre la formación de una elite política que perdurará a lo largo de toda la historia de Córdoba. Sobre las transformaciones de ese patriciado en consonancia con el desarrollo industrial cordobés posterior a la caída de Perón, se ocupa Tcach en su texto «Los Nores Martínez: policía y sacristía en una ciudad de enclave (Córdoba 1962- 63)» período caracterizado por la represión política y el oscurantismo cultural.

Además de los partidos políticos también son abordados otros actores relevantes para la política cordobesa como la Iglesia Católica que, aunque no consiguió organizar su propio partido, como bien analizan Silvia Roitenburd en «Católicos sin partido. Consideraciones sobre el clericalismo de Córdoba (1880- 1919)» y Javier Moyano en uno de los artículos ya mencionados; pero el tema está presente prácticamente en todos los trabajos como un actor central más allá del partido gobernante y se trate de un período democrático o de dictadura y esto se observa desde principios del siglo XIX hasta fines del siglo XX.

Otros actores políticos clave, pero en este caso ya específicamente para la historia del siglo XX y especialmente de la segunda mitad, son los estudiantes universitarios y los sindicatos. Estos actores, si bien aparecen en prácticamente todos los artículos que abordan el siglo XX son analizados particularmente en los trabajos de Ofelia Pianetto «Sindicatos y política en Córdoba (19301943)» en el que analiza la organización del movimiento obrero cordobés en la etapa previa al peronismo; de Emilse Pons «El fracaso del proyecto autoritario en Córdoba y la eclosión de la movilización popular (1966- 1973)» en el que aborda el proceso de radicalización que se dio en estos sectores durante los años sesenta; de Leandro Inchauspe en «La lógica de la guerra interna en las primeras etapas de la revolución Argentina (1966-1970)» en que estudia el incremento de la violencia política y el recurso a la guerra interna como medio de negación del adversario y en el trabajo ya citado de Alicia Servetto, aunque cada uno de ellos lo hace desde diferentes perspectivas y modos de indagación.

El análisis del discurso y el estudio de los imaginarios y las representaciones es el que predomina en los trabajos 
que se acercaron a los años de dictadura y de recrudecimiento de la violencia política y allí podemos mencionar los artículos «La democracia de los mejores, no de la demagogia»: el orden político durante el «proceso de reorganización Nacional» de Marta Philp, «Empresarios de Córdoba y poder militar: diálogos en la intimidad» de María Clara Iribarne y el ya mencionado de Leandro Inchauspe. Trabajos en los que aparecen con claridad preguntas que todos aún nos hacemos para intentar comprender la trágica historia argentina de la segunda mitad del siglo XX, buscando entender las formas con las cuales los diferentes gobiernos dictatoriales pretendieron construir legitimidad. Así se indaga sobre el surgimiento de la lógica de guerra interna como justificación (Inchauspe), sobre la concepción de la política, la democracia y el orden que estaba detrás de sus discursos (Philp) y el apoyo que consiguieron de diferentes sectores de la sociedad, en particular el de los empresarios cordobeses (Iribarne).

Este breve repaso del contenido de esta compilación da cuenta de que Córdoba Bicentenaria es un libro representativo de toda una corriente de renovación teórica, temática y de perspectivas; nos muestra una historiografía en movimiento, en pleno proceso de producción y renovación. Es también el reflejo de una producción historiográfica de calidad, resultado de investigaciones históricas, en algunos casos de muchos años y que sin embargo, puede ser leído por diversos públicos, más allá del académico o especializado.

Por otra parte, este libro no trata únicamente de la historia de Córdoba sino que a través de cada uno de sus capítulos se cuenta, analiza e interpreta a la historia argentina desde un lugar diferente, descentrado de Buenos Aires. Los procesos históricos adquieren así otra perspectiva, se vuelven más complejos y, por ende, también más interesantes. Este libro también es un ejemplo de lo que ha conseguido el amplio desarrollo de la historia regional o provincial en los últimos años, complejizar a la historia argentina, cambiar el foco de análisis, encontrarse con nuevos problemas y diferentes preguntas.

El libro, entonces, además de ofrecer una reconstrucción historiográfica de distintos procesos históricos, de dar una interpretación sobre los mismos, constituye también una agenda de problemas y de formas de indagación. Resulta interesante poner atención a las fuentes utilizadas en los trabajos, entre las que se destacan en primer lugar los periódicos Los Principios, Córdoba, El Interior, El Eco de Córdoba y La Voz del interior, entre otros. Además de la prensa, en los diferentes capítulos se citan fuentes gubernamentales, judiciales, partidarias, de organizaciones sindicales y otras de carácter oral. En suma, Córdoba Bicentenaria es el fruto de la importante renovación historiográfica que atravesaron los centros de investigación de la Universidad Nacional de Córdoba a fines del siglo $\mathrm{XX}$, muestra un fuerte y sostenido trabajo en equipo, la consolidación de un campo profesional, muchas horas de archivo, de análisis, de debate y discusión. Al mismo tiempo, también es una prueba de la importante renovación de la historiografía argentina de los últimos años en la que los estudios en escalas regiona- 
les, provinciales, territoriales o locales han permitido enriquecerla.

En rigor, Córdoba Bicentenaria no agota todos los temas y períodos de la historia cordobesa pero tampoco es ese el propósito del libro sino, más bien, como indica su subtítulo, indagar sobre claves que permitan desentrañar y comprender ciertos rasgos de sus cultura política, de su identidad y del lugar de la provincia en el contexto de la historia argentina contemporánea. Objetivo que el libro alcanza con creces.
Al terminar la lectura de Córdoba Bicentenaria, se tiene la íntima convicción de entender más cabalmente los mitos o metáforas que -explicaba Tcach al inicio de la obra- se construyeron: desde la Córdoba patricia, clerical y conservadora a la rebelde y revolucionaria o reformista y democrática. Imaginarios y metáforas que aluden a rasgos de su identidad y de su cultura política como a los usos que desde diferentes espacios políticos hicieron y hacen de su historia. 